\title{
Microstructural characterisation related to hot tearing of Al-Cu sand mould castings
}

\author{
Mattia Merlin \\ Engineering Department, University of Ferrara, via Saragat 1, 44100 Ferrara (Italy) \\ mattia.merlin@unife.it
}

\begin{abstract}
In this paper, the hot tearing behaviour in $\mathrm{Al}-(4.8 \div 6) \% \mathrm{Cu}$ sand mould castings was preliminary investigated by means of microstructural examination and image analysis. A dog-bone pattern was employed for the realisation of the castings and three $\mathrm{Al}-\mathrm{Cu}$ alloys with different $\mathrm{Cu}$ and $\mathrm{Si}$ contents were used. The effects of the alloy composition and of different pouring temperatures on the hot tearing behaviour of the castings were evaluated. The quantity of the eutectic phase available during solidification is considered a very important parameter for the crack healing phenomenon, in fact the eutectic liquid flows into the hot tear areas and covers parts of the cracks. The hot tear paths and surfaces were observed by means of optical and scanning electron microscopes, which showed that the fracture surfaces were dominated by bridged grain boundaries and the presence of a liquid film, in particular at higher copper concentrations. Several samples were also drawn from the zones characterised by the maximum cross-section variation and the micrographs from the optical microscope were statistically analysed by means of commercially available image analysis software. The quantitative microstructural parameters of percentage, mean area and distribution of the eutectic phase were evaluated and correlated to the capacity of the eutectic liquid to heal open fractures caused by hot tearing for the examined alloys.
\end{abstract}

KEYWORDS. Al-Cu alloys; Sand mould casting; Hot tearing; Microstructure; Image analysis.

\section{INTRODUCTION}

I $\mathrm{n}$ foundry practice the occurrence of solidification defects limits the production and performance of cast components. Hot tearing is one of the most serious solidification problems and, moreover, it has been known for a long time. Both ferrous and non-ferrous alloys can suffer the development of hot tears during solidification, particularly aluminium alloys. Great effort has been made over recent decades to understand the principal variables causing the development of hot tears; various authors have contributed to this phenomenon from both a theoretical and experimental point of view [1-4]. Hot tearing is related to the nucleation and development of macroscopic fissures during solidification, following interdendritic and intergranular paths inside the material, when the metal has not yet completely solidified. Unlike pure metals, alloys gradually transform from a liquid to a solid state over a certain temperature interval; therefore, the alloy consists of both a liquid and solid for a considerable period of time during casting. In this semi-solid state the material can be considered as a slurry at the highest temperatures, because it is liquid with some suspended solid particles, and then as a mush when the grains starts to interact with each other, generating a sort of skeleton [1]. Above the solidus temperature, when the material is in the mushy state, solid bridges are formed between neighbouring grains (usually dendritic in shape). The growth of a hot tear occurs in the last stage of solidification in the mushy state, while the volume fraction of solid is approximately $85-90 \%$, and it propagates either through the fully liquid film or through the liquid film and solid bridges, as has been suggested by several authors [5]. The generation of hot tears is principally due to the presence of two contemporary phenomena, which operate inside the alloy during solidification and also related to the geometry of the mould. Firstly, there is the contraction of the metal as it changes from a liquid to a solid, creating an 
internal state of stresses and strains, and, secondly, there is the presence of different solidification rates in different zones of the mould. Moreover, there is the tendency of alloying elements and impurities to segregate, thus producing enrichments at both macroscopic and microscopic levels [6]. Segregations determine a non-homogeneous mechanical, physical (fusion point) and chemical (corrosion resistance) behaviour of the alloy. The amount of eutectic liquid available in the last stages of solidification is very important, because a greater amount of eutectic increases the probability of shrinkage compensation by liquid feeding and the possibility of crack healing. It has been shown that the quantity of eutectic in Al-Cu alloys increases as the concentration of copper increases [7].

It is very difficult to perform a mathematical model that can reproduce the hot tearing phenomenon due to the complexity of both the mechanical behaviour of the semi-solid phase and the liquid flow in the interdendritic regions. Several authors have tried to understand the possible causes of hot tearing and have proposed models based on different critical parameters. For example, Novikov and Novik [8,9] reported that the grain boundary sliding is the main mechanism of deformation of a semi-solid body at low strain rates, while Pellini [10] suggested a hot tearing theory based on the strain accumulation in which the most important factor is the total strain in the hot spot region. Some authors suggested that the critical parameter is not the strain but the strain rate, with Prokhorov [1,11] being the first to propose a criterion based on this approach. Clyne and Davies paid more attention to the time spent in the mushy state [12]. Rappaz et al. [3] formulated a criterion based on afterfeeding (RDG criterion) that considered both the fluid flow and deformation of the solid skeleton, which is dependent on the permeability of the mushy zone.

Different experimental tests have been developed for assessing hot tearing susceptibility, with the aim to artificially produce internal stresses in the casting by restricting the free contraction of the alloy during solidification. The "ring mould test" is the most frequently used to compare the hot tearing tendency of aluminium alloys because this technique uses a simple equipment and experimenting [13-17]. Various other tests refer to the so-called "dog bone tests" and they have many variations with regard to the geometry of the mould. Wang et al. [18] developed a test for magnesium alloys where the equipment is designed to create an abrupt section change in the casting, while the test proposed by Vojtech et al. [19] for the study of aluminium alloys, involved the realisation of a casting with six fan-shaped bars with a triangular section. The test used for the study of copper alloys that was performed by Couture and Edwards is of greater interest $[20,21]$ and is the one carried out by Rosenberg et al. [22], who designed a mould for the realisation of castings composed of bars of different length produced from one single pouring.

The aim of this research is a preliminary study on the effect of different additions of copper and silicon and of different pouring temperatures on the hot tearing behaviour of the EN AB-21100 alloy. Several castings have been realised by means of the sand mould casting technique. The Couture-Edwards pattern, well-suited for copper alloys [20,21,23], has been used in order to verify its ability to also predict the hot tearing behaviour of aluminium alloys. A liquid penetrant inspection has been performed on the castings to detect surface cracks and then several specimens have been drawn from significative zones of the castings for metallographic analysis, carried out by optical microscopy (OM) and scanning electron microscopy (SEM). The micrographs acquired by optical microscopy and previously elaborated with image analysis software have been statistically processed to obtain a quantitative evaluation of the percentage, mean area and distribution of the eutectic phase. Finally, all data have been collected and plotted in order to understand the possible correlation between the microstructure and the tendency of the sand mould castings, realised with the examined alloys, to a complete crack caused by the hot tearing phenomenon.

\section{MATERIALS AND EXPERIMENTAL PROCEDURE}

\section{Alloys and casting system}

he commercial EN AB-21100 alloy (Alloy A) and two other variants (Alloy B and Alloy C), obtained by adding copper and silicon to the master alloy, have been selected for this investigation; the average compositions of the alloys are reported in Tab. 1. Alloy B differs from Alloy A for a copper content of 6wt.\%, while Alloy C differs from Alloy B for an increase in silicon content from 0.2wt.\% to 0.9wt.\%. The choice of EN AB-21100 alloy has been made based on its low castability and hot tearing susceptibility. The metal has been melted in an electric induction furnace at $780 \pm 5^{\circ} \mathrm{C}$ and the chemical composition has been analysed by means of optical emission spectroscopy (OES). Before casting, the melt was accurately degassed in order to guarantee high molten quality.

The two different pouring temperatures of $760^{\circ} \mathrm{C}$ and $700^{\circ} \mathrm{C}$, controlled by means of $\mathrm{K}$-type thermocouples, have been chosen; for each alloy and each pouring temperature, three experimental castings have been realised for a total number of 18 castings. 


\begin{tabular}{ccccccccccc}
\hline & $\mathrm{Si}$ & $\mathrm{Fe}$ & $\mathrm{Cu}$ & $\mathrm{Mn}$ & $\mathrm{Mg}$ & $\mathrm{Cr}$ & $\mathrm{Ni}$ & $\mathrm{Ti}$ & $\mathrm{Zn}$ & $\mathrm{Al}$ \\
Alloy A & 0.181 & 0.121 & 4.22 & 0.46 & $<0.01$ & $<0.01$ & $<0.003$ & 0.191 & 0.07 & bal. \\
Alloy B & 0.179 & 0.120 & 6.33 & 0.46 & $<0.01$ & $<0.01$ & $<0.003$ & 0.221 & 0.069 & bal. \\
Alloy C & 0.825 & 0.115 & 5.95 & 0.45 & $<0.01$ & $<0.01$ & $<0.003$ & 0.224 & 0.069 & bal. \\
\hline
\end{tabular}

Table 1: Average chemical compositions (wt.\%) of the alloys studied in the present work.

The sand moulds have been manufactured according to the Couture-Edwards design and the wood models used are depicted in Fig. 1. As it can be noted, the casting is composed of four bars of different lengths produced in one single pouring. Each bar has a spherical riser (feeder) on one side, which determines an abrupt section change with the presence of a local hot spot that generates high tensile stresses due to the contraction of the alloy along the bar during solidification. In order to have the same quantity of metal, each bar is constrained at the end by a flange that has been designed with a specific thickness according to the length of the bar itself. A useful parameter for the evaluation of the hot tearing susceptibility is the length of the bar; the greater the tendency of the alloy to generate hot tears, the shorter the bar that completely fails or becomes seriously damaged.

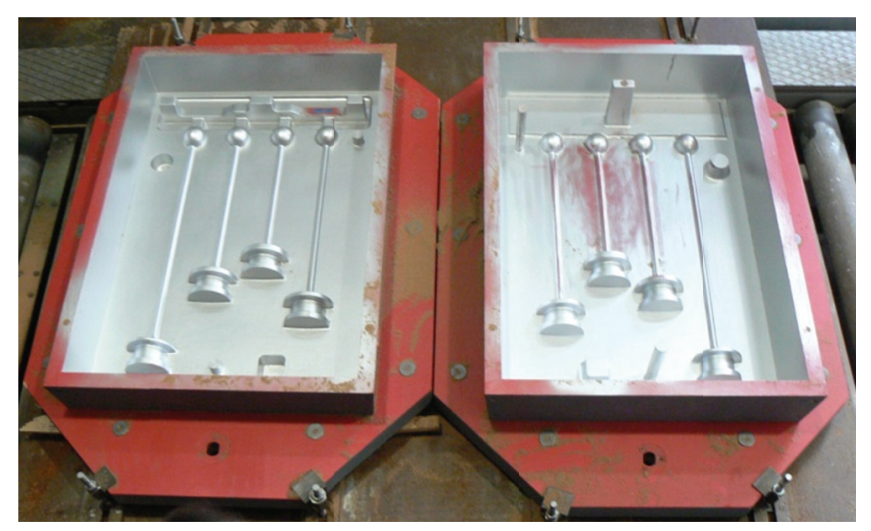

Figure 1: Wood model of the casting realised to evaluate the hot tearing behaviour of the alloys.

\section{Non-destructive analysis of the castings}

After solidification and cooling, the castings were extracted from the sand moulds; the cracks on all the bars were inspected visually and by a liquid penetrant test. Attention has been paid to the most critical zone, that is the hot spot near the spherical feeder. For example, a photo of one casting has been reported in Fig. 2; a zoom of a completely cracked bar is also depicted in the same figure.

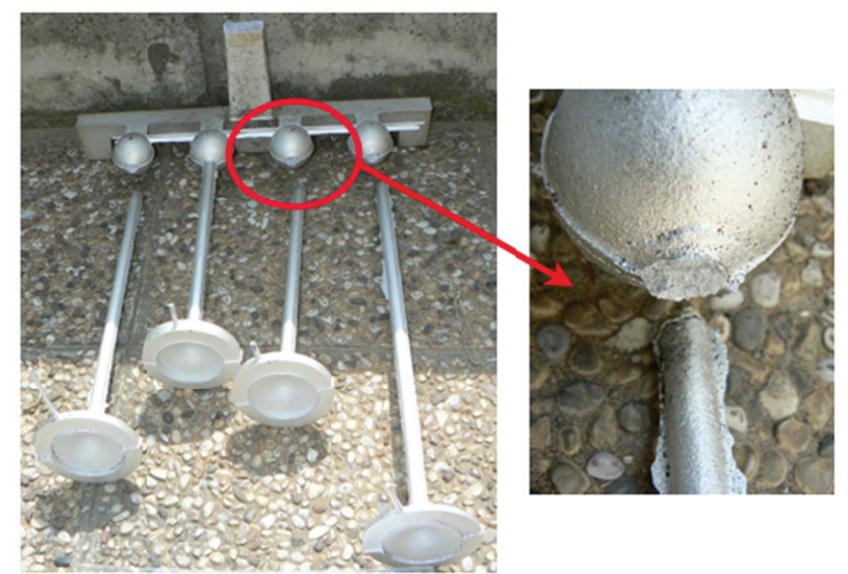

Figure 2: Photo of a casting produced in Alloy B with a pouring temperature of $760^{\circ} \mathrm{C}$. 
Five categories of hot tear severity have been considered: no crack, light crack, crack, severe crack and complete crack. In order to identify each single bar and to refer it to the specific casting a special nomenclature has been considered. The classification of the bars consists of a letter (A, B, C), which refers to the alloy, and three numbers: the first indicating the casting $(1,2,3)$, the second specifying the pouring temperature $\left(1=700^{\circ} \mathrm{C}\right.$ and $\left.2=760^{\circ} \mathrm{C}\right)$ and the third referring to the number of the bar in ascending order from the longest to the shortest $(1,2,3,4)$. All the information obtained from the macroscopical observations of the castings has been summarised in Tab. 2; the completely cracked bars are underlined in green. In Fig. 3, there is a photo clearly showing the detection of the discontinuity relating to a hot spot, performed by the non-destructive liquid penetrant testing method.

\begin{tabular}{|c|c|c|c|c|c|}
\hline & & $\operatorname{bar}^{\circ} 1$ (longest) & $\operatorname{bar} n^{\circ} 2$ & $\operatorname{bar} n^{\circ} 3$ & $\operatorname{bar}^{\circ} 4$ (shortest) \\
\hline \multirow{6}{*}{ Alloy A } & A.1.1 & $\mathrm{x}$ & $\mathrm{x}$ & $\mathrm{x}$ & $ハ ハ ハ ハ ハ ハ$ \\
\hline & A.1.2 & $\mathrm{x}$ & $\mathrm{x}$ & $\mathrm{x}$ & $ハ ハ ハ 八$ \\
\hline & A. 2.1 & ----- & $ハ ハ ハ ハ ハ \wedge$ & $\mathrm{x}$ & $\mathrm{x}$ \\
\hline & A. 2.2 & $\mathrm{x}$ & $\mathrm{x}$ & $\mathrm{x}$ & $ハ 八 ハ 八$ \\
\hline & A.3.1 & $\mathrm{x}$ & $\mathrm{x}$ & $\mathrm{x}$ & $\mathrm{x}$ \\
\hline & A. 3.2 & $\mathrm{x}$ & $\mathrm{x}$ & $ハ 八 \bigwedge ハ ハ \bigwedge$ & $ハ ハ$ \\
\hline \multirow{6}{*}{ Alloy B } & B.1.1 & $\mathrm{x}$ & $\mathrm{x}$ & 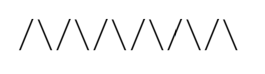 & $ハ ハ$ \\
\hline & B.1.2 & $\mathrm{x}$ & $\mathrm{x}$ & $ハ ハ ハ ハ ハ \wedge$ & $ハ ハ ハ ハ$ \\
\hline & B.2.1 & $\mathrm{x}$ & $\mathrm{x}$ & $\mathrm{x}$ & $ハ 八$ \\
\hline & B.2.2 & $\mathrm{x}$ & $ハ ハ ハ ハ ハ \wedge$ & $ハ ハ ハ ハ ハ \wedge$ & $ハ ハ$ \\
\hline & B.3.1 & $\mathrm{x}$ & $\mathrm{x}$ & $ハ ハ ハ ハ ハ 八$ & $ハ 八$ \\
\hline & B.3.2 & $\mathrm{x}$ & $\mathrm{x}$ & $ハ ハ ハ ハ ハ \wedge$ & $ハ ハ$ \\
\hline \multirow{6}{*}{ Alloy C } & C.1.1 & $ハ ハ ハ ハ ハ \wedge$ & $ハ ハ ハ ハ$ & $ハ ハ$ & ------ \\
\hline & C.1.2 & $\mathrm{x}$ & $ハ 八$ & $ハ ハ ハ ハ$ & ------ \\
\hline & C.2.1 & $ハ ハ ハ ハ ハ \bigwedge$ & $ハ ハ ハ ハ ハ$ & ----- & ----- \\
\hline & C. 2.2 & $ハ ハ ハ ハ ハ \wedge$ & $ハ ハ ハ ハ$ & $ハ ハ$ & ------ \\
\hline & C.3.1 & 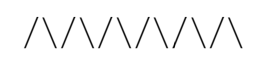 & 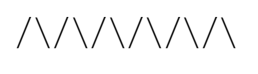 & $ハ ハ ハ ハ$ & ----- \\
\hline & C. 3.2 & $ハ 八 ハ ハ ハ ハ$ & $ハ 八$ & $ハ 八$ & ----- \\
\hline
\end{tabular}

Table 2: Results obtained from visual and liquid penetrant inspections [no $\operatorname{crack}(-----), \operatorname{light} \operatorname{crack}(\bigwedge \bigwedge), \operatorname{crack}(\bigwedge \bigwedge \bigwedge \bigwedge)$, severe $\operatorname{crack}(\bigwedge \bigwedge \bigwedge \bigwedge \bigwedge \bigwedge)$ and complete $\operatorname{crack}(\mathrm{x})]$.

Microstructural analysis and fractography

The non-destructive considerations have been useful in the selection of the representative samples drawn as close as possible to the hot tear location or to the initiation of hot tears. Samples, taken along the axial and the radial cross sections 
of the bars, have been prepared for the metallographic inspection performed by the Leica MEF4M optical microscope $(\mathrm{OM})$. The microstructure has been examined and important information concerning fracture paths, crack healing effects and the presence of secondary phases and fractured bridges involved in the hot tearing process have been obtained.

The investigation of the tear surface fractography, in particular with the aim of understanding the role of the eutectic phase in the process, has been carried out by scanning electron microscopy (SEM) and by energy dispersive X-ray spectroscopy (EDS).

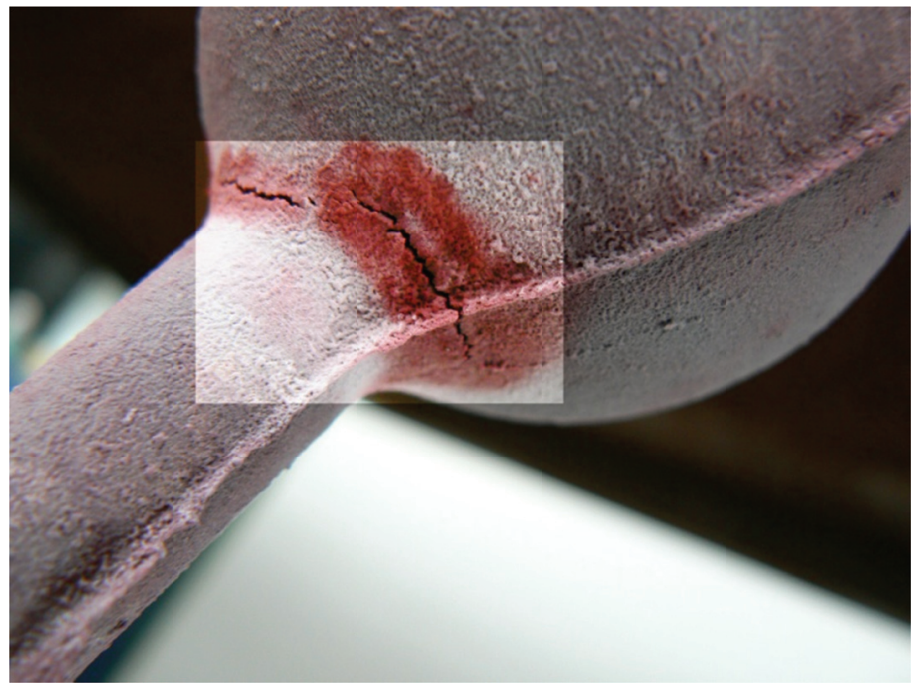

Figure 3: Photo of a hot tear revealed by the liquid penetrant testing method.

\section{Image analysis}

Image-Pro Plus software has been used to carry out a preliminary image analysis study with a statistical approach. Different microstructural parameters, such as quantity, mean area and mean minimum-radius of the eutectic phase have been calculated, taking into account the chemical compositions of the examined alloys, the pouring temperatures and the different lengths of the bars. The minimum-radius is an important parameter reporting the minimum distance between the centroid of each portion of the eutectic phase and its perimeter, and it can therefore be considered as related to a possible concentration of stresses. The correlation between the calculated microstructural parameters and the cracked or uncracked bars has been evaluated.

For performing this kind of analysis, all the 18 castings have been taken into account and three specimens have been drawn from all the bars in the hot spots near the spherical feeder. From each sample, three significant micrographs revealing its microstructure have been acquired by optical microscope and subsequently elaborated by the software.

\section{RESULTS}

\section{Microstructural analysis}

$\checkmark$ he typical microstructure of the sand cast $\mathrm{Al}-\mathrm{Cu}$ alloys consists of the primary $\alpha$ - $\mathrm{Al}$ phase and an eutectic mixture of $\alpha-\mathrm{Al}$ with the secondary phase $\mathrm{CuAl}_{2}$. When comparing the microstructures of corresponding samples drawn from castings poured at different temperatures, no evidence of grain growth due to a higher pouring temperature was found. In Fig. 4 the microstructure of the eutectic phase can be noted; according to literature [24] and also by EDS analysis secondary phases, in particular Fe-rich intermetallics like $\mathrm{Al}_{7} \mathrm{Cu}_{2} \mathrm{Fe}$ with the typical needle shape, have been identified in the samples. The presence of a greater amount of silicon in Alloy $\mathrm{C}$ has determined the precipitation of AlFe-Si secondary phases, which in general contributes to a decrease in mechanical properties, especially at high temperatures [25].

Hot tears are present in all the analysed samples even though it has been observed that the greater the amount of eutectic available, the higher the probability of shrinkage compensation by liquid feeding. In the micrographs of Fig. 5 examples of hot tears are reported that are a) partially or b) totally healed by the eutectic liquid during the last solidification. As it can be noted, the development of cracks during solidification follows interdendritic and intergranular paths inside the material. 


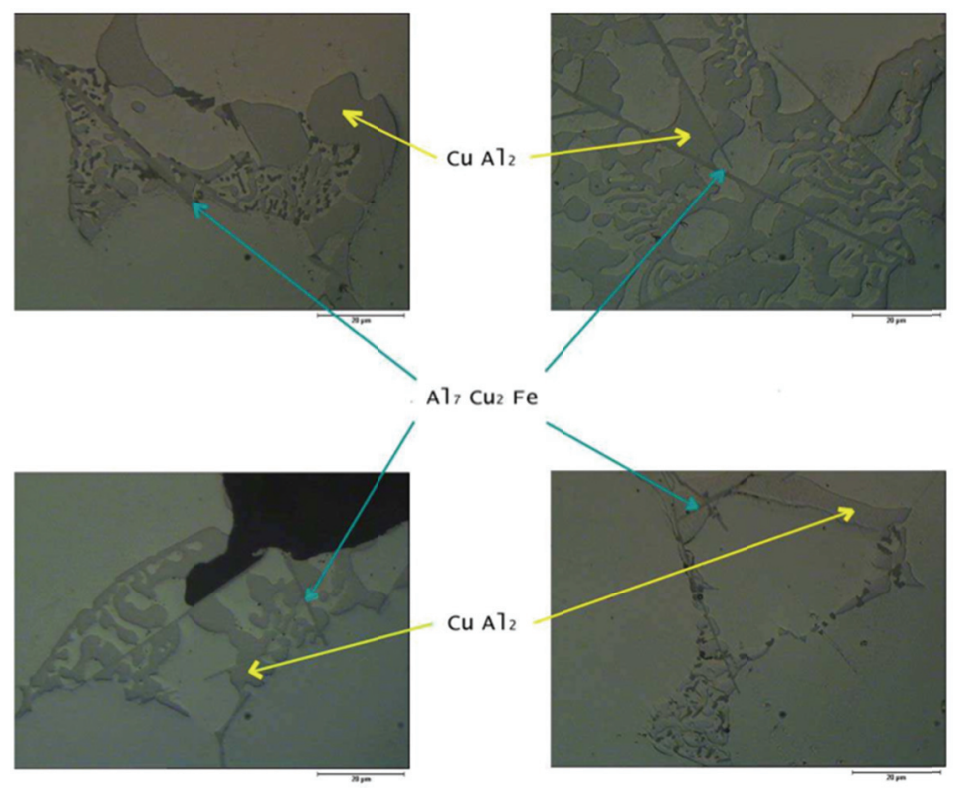

Figure 4: Optical micrographs showing the microstructure of the eutectic mixture and the presence of secondary phase particles.

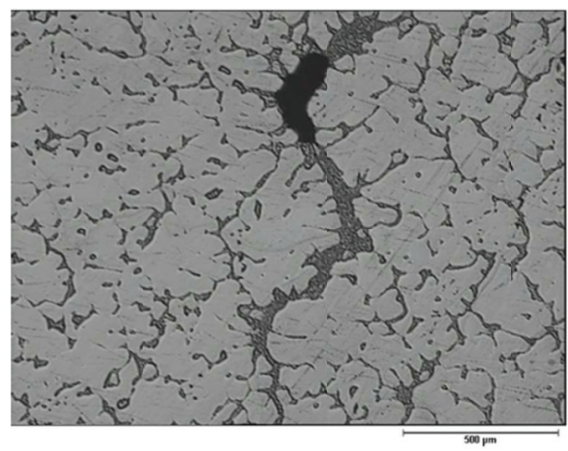

(a)

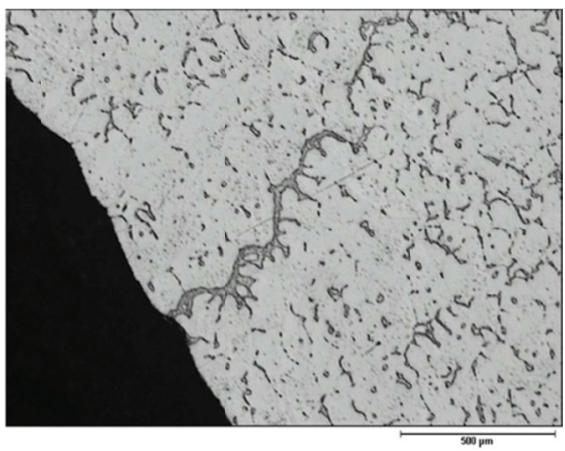

(b)

Figure 5: Hot tears in a sample drawn in C.2.1.3: a) partially healed and b) totally healed.

If the amount of eutectic mixture is small and is not enough to cover the grain boundaries and to form a continuous liquid film, the grains try to coalesce by bridging; the presence of fractured bridges indicates the propagation of interdendritic hot tears at the last stage of solidification. In the optical micrographs of Fig. 6 a) and b) several solid bridges between adjacent dendrite arms can be identified. It is well-known that the decrease of copper concentration causes an increase in the fraction of solid bridges on the hot tear surfaces [7]. Moreover, the microstructural analysis showed that there was no significative improvement in the hot tearing behaviour with the moderate addition of silicon in Alloy $\mathrm{C}$ with respect to Alloy B.

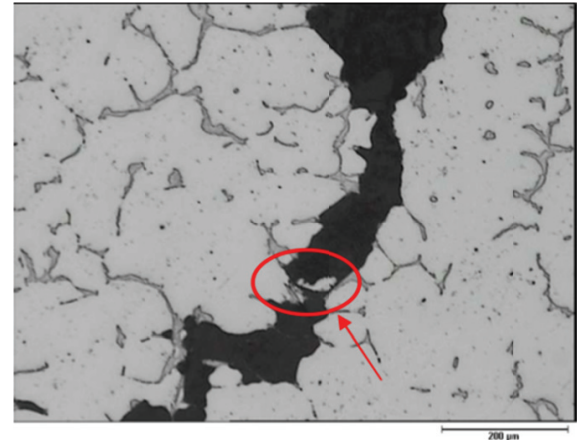

(a)

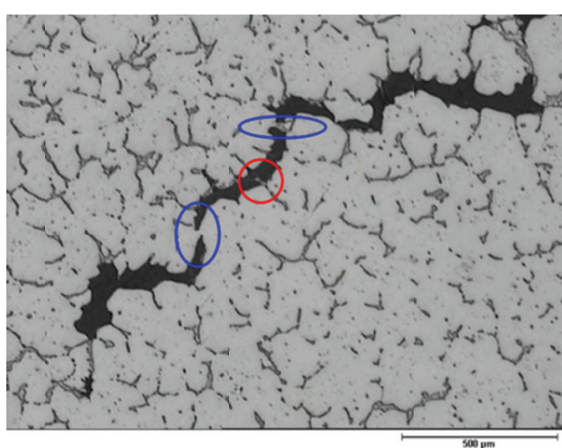

(b)

Figure 6: Solid bridges in samples drawn from a) A.3.1.1 and b) A.3.2.1 bars.

Fractured and no-fractured bridges are depicted in red and blue, respectively. 


\section{SEM analysis}

Scanning electron microscopy has been used to investigate the hot tear surface fractography. As can be seen in Fig. 7, the SEM analysis of a hot tear reveals its typical intercrystalline path, which is the result of interdendritic separation. The fracture surface of alloys containing significant amounts of copper is typically smooth due to the presence of an eutectic film in the last stages of solidification, which covers at least part of the surface; an example is depicted in the micrograph of Fig. 8.

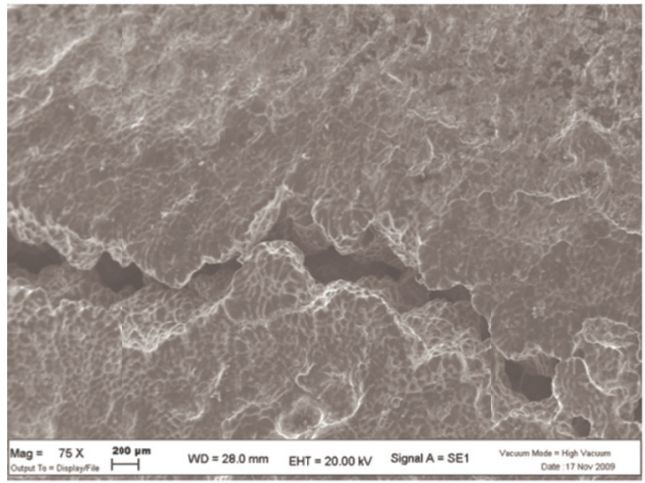

Figure 7: Hot tear at low magnification in a sample drawn from A.2.1.1.

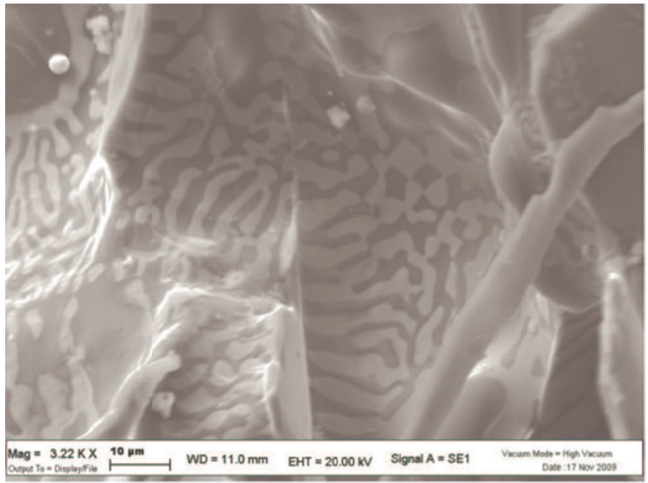

Figure 8: Fracture surface of a sample drawn from C.1.2.1.

Precipitates of secondary phases have been found on the fracture surfaces of the samples analysed. An example is shown in Fig. 9 for a sample drawn from the hot spot in the C.3.2.1 bar. EDS analysis has revealed the presence of a brittle AlFe-Si platelet. The presence of these second phase platelets can contribute to limit the flow of the eutectic liquid in the interdendritic cracks.

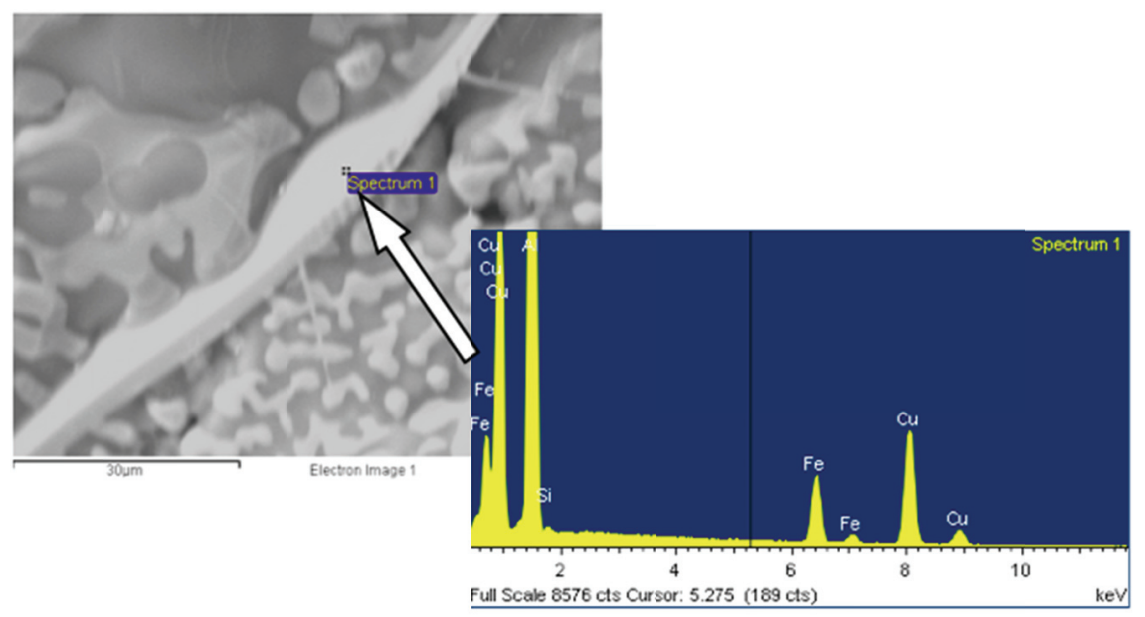

Figure 9: SEM micrograph of a Al-Fe-Si platelet with EDS spectrum.

Several solid bridges have been found on the hot tears surfaces, in particular in samples drawn from castings obtained with Alloy A. The fraction of bridged grain boundaries depends mostly on the alloying content and tends to be greater in less alloyed materials [26]. Micrographs of fractured bridges observed in samples taken from the A.2.2.3 and A.3.1.1 bars are reported in Fig. 10 and Fig. 11, respectively.

It is important to compare the results here obtained with those shown by Suyitno et al. in [27], who studied the hot tearing behaviour of billets cast from Al-Cu alloys with different copper concentrations and produced by DC casting. In their work, no signs of hot tears in alloys that contained more than 4wt.\% copper have been found. On the contrary, in this research, Alloy A that contains 4.8wt.\% copper is very susceptible to hot tearing and this is probably due to the geometrical features of the Couture-Edwards pattern used to test the hot tearing behaviour. For higher copper contents 
the effect of the greater eutectic liquid available in the last stages of solidification strongly contributes to the healing of the hot tears.

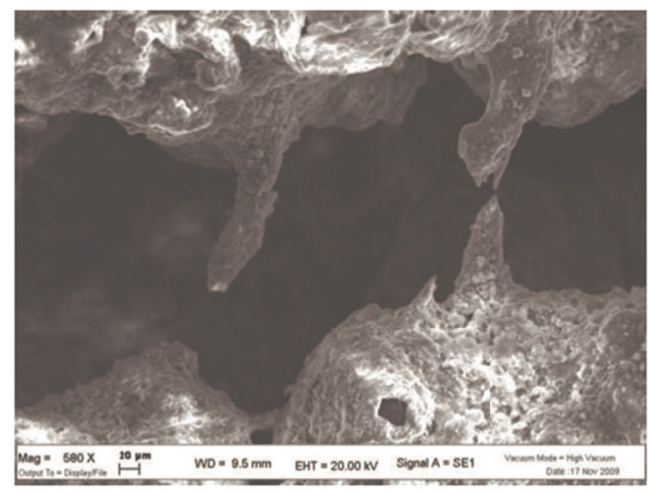

Figure 10: Fractured solid bridges in sample A.2.2.3.

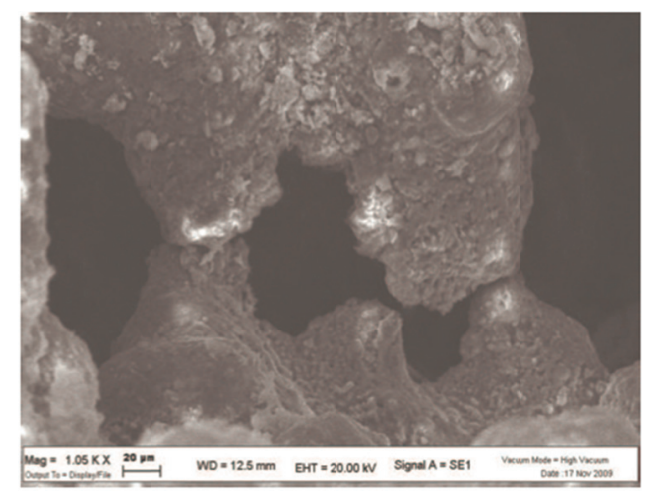

Figure 11: Fractured solid bridges in sample A.3.1.1.

\section{Image analysis}

As mentioned in Materials and experimental procedure: Image analysis, Image-Pro Plus software has been used to preliminary study possible correlations between microstructural parameters and the hot tearing behaviour of the castings. Several micrographs have been obtained by optical microscopy in the hot spot near the spherical feeder of all bars and then processed by means of image analysis software. Quantitative information concerning the percentage, mean area and distribution in terms of mean minimum-radius of the eutectic phase has been carried out. Using a statistical approach, all data have been collected and correlated with the pouring temperature, the cracked and un-cracked bars and the composition of the alloys. The correlations suggest the importance of the capability of the eutectic liquid to heal open fractures; the increase in both the percentage and the coarseness of the eutectic phase contributes to the soundness of the castings that is to the decrease of the number of cracked bars. Moreover, an interesting result concerns the effect of the pouring temperature: at an equal eutectic percentage, the castings poured at the highest temperature present a coarse eutectic phase, independently of the length of the bars and the alloy.

Comparing the results obtained from the samples drawn from cracked and un-cracked bars of all the castings poured at $760^{\circ} \mathrm{C}$, the cracked bars are characterised by a smaller percentage of eutectic phase than the un-cracked ones, as depicted in the diagram of Fig. 12. The mean value of the percentage of the eutectic in the cracked bars is $11.65 \%$ with a standard deviation of $4.73 \%$, while in the un-cracked bars it is $14.54 \%$ with a standard deviation of $5.4 \%$. The result is general and comprehensive of data obtained from samples drawn from all the castings; this justifies the high standard deviations. As can be seen from the diagram, among the un-cracked bars the shortest bars $\left(n^{\circ} 3\right.$ and $\left.n^{\circ} 4\right)$ are characterised by more amount of eutectic phase than the longest ones $\left(n^{\circ} 1\right.$ and $\left.n^{\circ} 2\right)$. Accordingly, the geometrical effect related to the different length of the bars seems to play an important role in the eutectic liquid flow and, as a consequence, in the crack healing effect in the last stages of solidification.

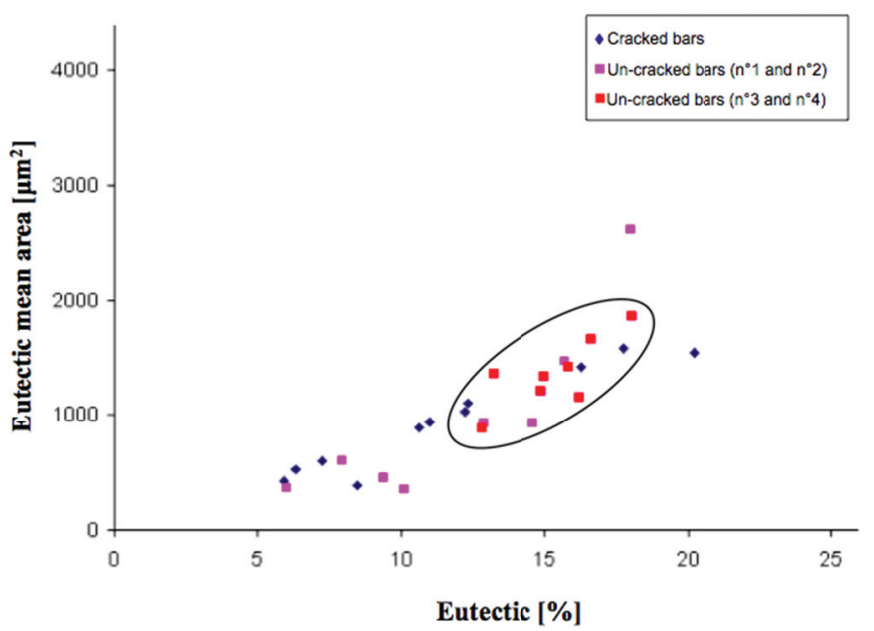

Figure 12: Eutectic percentage in the samples drawn from cracked and un-cracked bars of all the castings poured at $760^{\circ} \mathrm{C}$. 
The same correlation between the percentage and mean area of the eutectic phase has been studied by separating the data of each alloy; this relation for Alloy A is depicted in Fig. 13. As can be seen, if the pouring temperature is increased, the quantity of eutectic phase available to heal the hot tears is both greater and coarser. The same trend has also been obtained from Alloy B and this is in good agreement with the visual and liquid penetrant inspections. The increases of the pouring temperature and of the copper content in the alloy contribute to the reduction of the number of completely cracked bars caused by the development of hot tears. No further significant information has been obtained from the statistical processing of the micrographs of the samples drawn from the castings produced in Alloy $\mathrm{C}$, confirming the microstructural analysis explained in section Microstructural analysis; it seems that small silicon additions (0.7wt.\%) have no great influence in the hot tearing behaviour of the examined alloy. Perhaps, the presence of silicon in alloy $\mathrm{C}$ has had two conflicting consequences: a positive effect due to the higher castability of the alloy than Alloy A and Alloy B, and a negative effect due to the precipitation of $\mathrm{Al}-\mathrm{Fe}-\mathrm{Si}$ platelets that can contribute to limit the flow of the eutectic liquid in the interdendritic zones. Despite the results obtained by the metallographic analysis and the subsequent statistical processing of data, from the visual and the liquid penetrant inspections (Tab. 2) the castings realised in Alloy C present the lowest number of completely cracked bars.

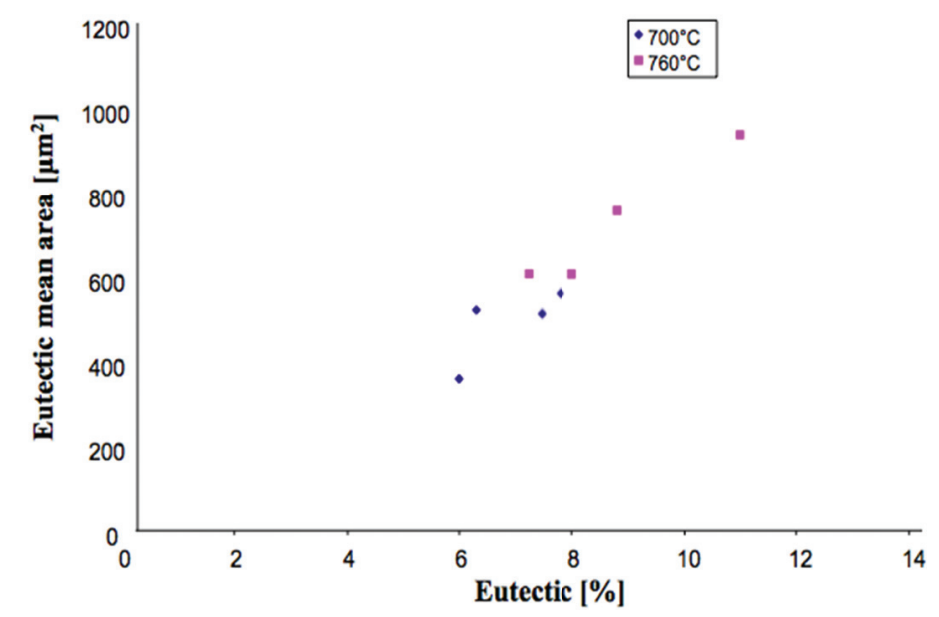

Figure 13: Correlation between percentage and mean area of the eutectic phase in Alloy A.

The mean minimum-radius of the eutectic phase calculated for both cracked and un-cracked bars has been considered as a parameter related to the possible concentration of stresses in the material; its lower value in cracked bars suggests that it could be a useful index for the evaluation of the susceptibility to hot tearing (Fig. 14). Moreover, considering the results obtained in un-cracked bars, it seems that there was no significative correlation related to the different length of the bars.

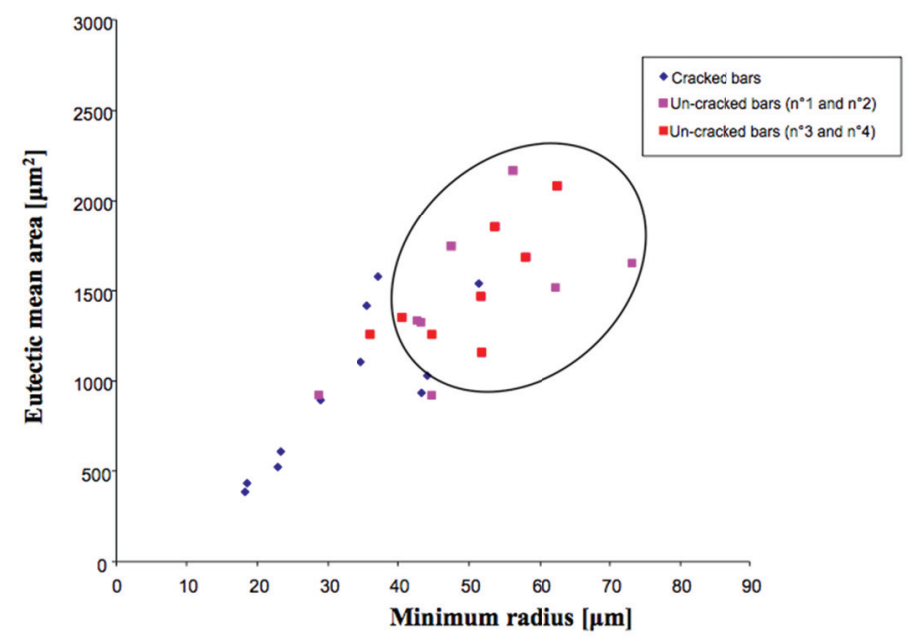

Figure 14: Correlation between mean area and minimum radius of the eutectic in cracked and un-cracked bars for castings poured at $760^{\circ} \mathrm{C}$. 


\section{CONCLUSIONS}

$\mathrm{B}$ ased on the obtained results, the following conclusions can be drawn as regards the hot tearing behaviour of alloy EN AB-21100 and of its two foundry variants containing additions of copper and silicon:

- The Couture-Edwards test has proved to be suitable for the study of the hot tearing behaviour of aluminium foundry alloys thanks to the presence of hot spots generated by a critical section change between spherical feeders and bars of different lengths.

- Several solid fractured bridges have been found on the hot tear surfaces, especially in Alloy A containing 4.8wt.\% in copper and therefore, among the examined alloys, characterised by the lowest amount of eutectic liquid available in the last stages of solidification.

- In the alloys with the highest copper content the crack healing effect due to the distribution and coarseness of the eutectic phase has been revealed by means of microstructural analysis of several samples drawn from the hot spots.

- A moderate increase in the contents of silicon in the alloy did not significantly contribute to an increase of the crack healing phenomenon; even though it seems that silicon did not affect the distribution of the eutectic phase, the castings in Alloy $\mathrm{C}$ presented the lowest number of cracked bars.

- A preliminary statistical study has been performed by means of image analysis software on the various micrographs drawn from the castings relating to the hot spots; it has been very useful to understand possible correlations between the microstructure and the tendency of $\mathrm{Al}-\mathrm{Cu}$ sand mould castings to a complete failure due to the hot tearing phenomenon. Obviously, to confirm these results the analysis needs to be performed on a greater number of samples.

- Further studies are under consideration to correlate the obtained information with the stress state of the material during the solidification of the alloys. The calculation of a hot tearing indicator, based on the surface fraction of hot tears in the hot spots, will be soon related to the quantitative microstructural parameters presented in this paper.

\section{ACKNOWLEDGEMENT}

7 he author wishes to thank Fonderia Scacchetti Leghe Leggere srl of San Felice sul Panaro (Modena - Italy) for the realisation of the aluminium castings. Many thanks are also due to Dr. Lorenzo Pivetti, Dr. Alessandro Cavallini, Dr. Gaudenzio Preti and Dr. Enrico Santarato for their experimental contribution to this research.

\section{REFERENCES}

[1] D. G. Eskin, Suyitno, L. Katgerman, Progress in Materials Science, 49 (2004) 629.

[2] J. Campbell, Casting: The New Metallurgy of Cast Metals, Butterworth-Heinemann 2nd edition, Oxford (2003).

[3] M. Rappaz, J. M. Drezet, M. Gremaud, Metallurgical and Materials Transaction A, 30, (1999), 449-455.

[4] M. Rappaz, I. Farup, J. M. Drezet, In: Proceedings of the Merton C. Flemings Symposium on Solidification and Materials Processing, TMA (The Minerals, Metals \& Materials Society) (2001).

[5] A. B. Phillion, S. L. Cockcroft, P. D. Lee, Materials Science and Engineering A, 491 (2008), 237.

[6] D. G. Eskin, Suyitno, J. F. Mooney, L. Katgerman, Metallurgical and Materials Transactions A, 35A (2004) 1325.

[7] Suyitno, D. G. Eskin, L. Katgerman, Materials Science and Engineering A, 420 (2006) 1.

[8] I. Novikov, Hot shortness of non-ferrous metals and alloys, Moscow, Nauka, (1966) 299.

[9] I. Novikov, F. S. Novik, Doklady Akad Nauk SSSR, Ser Fiz, 7 (1963) 1153.

[10] W. S. Pellini, Foundry, 80 (1952) 124.

[11] N. N. Prokhorov, Russian Castings Production, 2 (1962) 172.

[12] T. W. Clyne, G. J. Davies, J. British Foundry, 74 (1981) 65.

[13] H. Chadwick, Casting Metal, 4(1) (1991) 43.

[14] W. Patterson, S. Engler, Aluminium, 35 (1959) 124.

[15] A. R. E. Singer, P. H. Jennings, J. Institute of Metals, 73 (1947) 197.

[16] M. Drezet, M. Rappaz, In: International Conference Modeling of Casting, Welding and Advanced Solidification Processes VIII, San Diego (USA), (1998).

[17] D. Warrington, D. G. McCartney, Cast Metals, 2(3) (1989) 134. 
[18] Y. Wang, B. Sun, Q. Wang, Y. Zhu, W. Ding, Materials Letters, 53(1) (2002) 35.

[19] D. Vojtech, J. Serak, O. Eckert et al., Materials Science and Technology, 19 (2003) 757.

[20] A. Couture, J. O. Edwards, Trans. AFS., 74 (1966) 709.

[21] A. Couture, J. O. Edwards, AFS Cast Metals Research Journal, (1967) 57.

[22] R. A. Rosenberg, M. C. Flemings, H. F. Taylor, Trans. AFS., 68 (1960) 518.

[23] M. Merlin, G. L. Garagnani, G. Venturi Pagani Cesa, La Metallurgia Italiana, Honegger, Milano, $7 / 8$ (2007) 35.

[24] E. Di Russo, The atlas of microstructures of aluminium casting alloys, Edimet Ed., Brescia (1993).

[25] N. Han, X. F. Bian, et al., Acta Metallurgica Sinica (Engl. Lett.), 19(6) (2006) 405.

[26] Y. Ju, L. Arnberg, Int. J. Cast Metals Research, 16 (2003) 522.

[27] Suyitno, D. G. Eskin, V. I. Savran, L. Katgerman, Metallurgical and Materials Transaction A, 35A (2004) 3551. 